\title{
Vocal and self-perception effects of straw phonation exercises
}

\author{
Larissa Rezende da Paixão ${ }^{1}$ \\ https://orcid.org/0000-0002-7818-4941 \\ Márcia Cristina Bebiano Tannes ${ }^{1}$ \\ https://orcid.org/0000-0001-7540-6740 \\ Bárbara Oliveira Souza ${ }^{2}$ \\ https://orcid.org/0000-0002-8489-9660 \\ Lorena Luiza Costa Rosa Nogueira ${ }^{2}$ \\ https://orcid.org/0000-0002-0645-8173 \\ Renata Maria Moreira Moraes Furlan ${ }^{3}$ \\ https://orcid.org/0000-0001-7588-9316
}

\begin{abstract}
Centro Universitário Metodista Izabela Hendrix, Belo Horizonte, Minas Gerais, Brasil.

2 Universidade Federal de Minas Gerais UFMG, Programa de Pós-graduação em Ciências Fonoaudiológicas, Belo Horizonte, Minas Gerais, Brasil.

${ }^{3}$ Universidade Federal de Minas Gerais UFMG, Faculdade de Medicina, Departamento de Fonoaudiologia, Belo Horizonte, Minas Gerais, Brasil.
\end{abstract}

Study carried out at the Centro Universitário Metodista Izabela Hendrix Belo Horizonte, Minas Gerais, Brazil.

Conflict of interests: Nonexistent

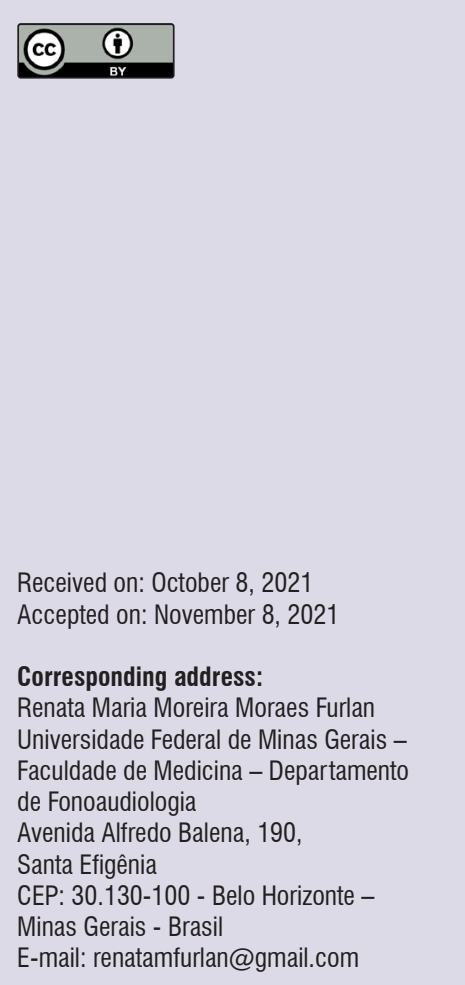

\section{ABSTRACT}

Purpose: to assess the acoustic and self-perceived voice changes in women with and without voice symptoms after 1, 3, 5, and 7 minutes of straw phonation exercises.

Methods: a total of 30 women aged 18 to 39 years participated in the study -17 with and 13 without voice symptoms. The participants filled in the visual analog scale on self-perceived voice discomfort. The sustained vowel $/ \varepsilon /$ was recorded in maximum phonation time before $(\mathrm{m} 0)$ and after the first, third, fifth, and seventh minute performing straw phonation exercises. The maximum phonation time was measured, and an acoustic analysis was made, encompassing the following parameters: the number of harmonics, fundamental frequency, noise, glottal-to-noise excitation ratio (GNE), jitter, and shimmer. The Friedman and Wilcoxon tests were used to compare each parameter at the different moments, and the Mann-Whitney test, to compare the groups. The 5\% significance level was set for the analyses.

Results: no changes were found in either the acoustic variables or the self-perception of voice comparing the moments before and after the exercises in either group. The comparison between the groups revealed that the one with voice symptoms had lower GNE and higher noise values at the second moment performing the technique.

Conclusion: the straw phonation did not cause acoustic or self-perceived voice changes in women with and without voice symptoms. The comparison between the groups showed that the women with symptoms had lower GNE and higher noise values than those without symptoms, after 1 minute performing straw phonation.

Keywords: Voice; Voice Training; Speech Acoustics; Speech Therapy 


\section{INTRODUCTION}

The semi-occluded vocal tract exercises (SOVTE) are low-cost techniques ${ }^{1}$ often used in speech-languagehearing clinical practice as a voice therapy resource ${ }^{2-5}$. Their purpose is to create resistance to airflow (acoustic impedance) and thus, improve vocal efficiency ${ }^{5-7}$. There are many variations in how to perform these exercises, but the main aspect that characterizes them as SOVTE is the semi-occluded lips exercise ${ }^{8}$. This occlusion causes the sensation of mild resistance to the passage of sound, making the technique easier to perform without overloading the glottis ${ }^{8,9}$. The increase in pressure in the vocal tract caused by tube phonation generates a counter-resonance, which in turn exert adduction and abduction strength on the vocal folds. It muffles the mucosal wave movement of the vocal folds, easing the tension and collision trauma caused when they come together ${ }^{7,9-12}$.

The physiological sequence promoted by the SOVTE improves the pneumo-phono-articulatory coordination, diminishes glottal compression and supraglottal constriction, and expands the vocal tract, favoring

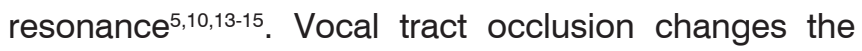
inner pressure in relation to the atmospheric pressure and the glottal configuration of the vocal tract, improving articulatory and vocal resonance characteristics ${ }^{9,16}$.

The SOVTE benefits not only speech but also singing, as it helps adjust effortless voice use ${ }^{17}$. Tube phonation has also been used by singers ${ }^{4}$ as a vocal warm-up to make voice quality clearer and louder ${ }^{18}$.

One of the SOVTE modalities involves resonance tubes ${ }^{19}$, such as straws, which can be used in two ways: leaving the distal end of the tube free in the air or dipped in water ${ }^{11,15,19}$. In both cases, the tube must remain in the person's mouth, as if it were an artificial extension of the vocal tract ${ }^{3}$. Studies point out that exercises involving resonance tubes can also be used as a therapeutic resource in cases of voice disorders ${ }^{20,21}$.

Good voice quality and rich harmonics require the tunica mucosa of the vocal folds to be elastic and flexible ${ }^{22}$. The physiology of phonation involves the vibration of the vocal folds, which begins when the air breathed out gets in contact with the adducted vocal folds, displacing their tunica mucosa and forming successive top-to-bottom attraction and repulsion waves. The mucosal wave movement depends on the transglottal airflow. Under normal circumstances, the air glides on the laryngeal walls with little friction ${ }^{22}$. The passage of the air current through the glottis in phonation causes not only the sound signal modulated by the glottal mechanism but also additional noise, which can be measured and contrasted with the sound signal, using the glottal-to-noise excitation ratio $(\mathrm{GNE})^{23,24}$.

Although straw phonation is known for its beneficial effects on both the sensations and the quality of voice production, the literature still has little information available about the ideal technique performance time. This paper aimed to assess the acoustic changes and self-perceived voice quality in women with and without voice symptoms, obtained after 1, 3, 5, and 7 minutes practicing straw phonation.

This study hypothesizes that the straw phonation technique combined with vocal emission can have positive voice acoustic effects and provide a more comfortable self-perceived vocal emission, with ideal minimum and maximum technique performance time to provide the said benefits without vocal fatigue.

\section{METHODS}

This is a cross-sectional, experimental, analytical study with a convenience sample, approved by the Research Ethics Committee of the Centro Universitário Metodista Izabela Hendrix (Izabela Hendrix Methodist University Center), Brazil, under number 2.850.578 (CAAE 96408818.1.0000.5096).

Female subjects aged 18 to 45 years, with and without voice symptoms, were invited to participate in the study. The exclusion criteria were as follows: people with a cardiovascular, neurological, or auditory disease that might interfere with phonation; with a cleft lip and/or palate, facial or costal arch fractures, acute asthma, chronic obstructive pulmonary disease, bronchospasm, severe renal impairment, or untreated pneumothorax; and smokers. The people who did not sign the informed consent form, who had been previously submitted to speech therapy, or who did not finish all the stages in the study were also excluded.

The Voice Symptom Scale (VoiSS) ${ }^{25}$ was used to identify possible voice symptoms and characterize the sample. It is an objective scale, easily calculated and interpreted, made up of 30 multiple-choice questions. The subjects answer the questionnaire autonomously, checking one of the following answers in each question: never, rarely, sometimes, almost always, or always - which are respectively graded from 0 to 4 points on the scale. Those whose total score was equal to or higher than 16 points comprised the group with voice symptoms, following the standardization proposed by Moreti ${ }^{25}$. 
Each participant filled in a visual analog scale ${ }^{26}$ (VAS) and was instructed to check their perception of the level of voice discomfort. The VAS had a numbered line - the left end representing the absence of voice discomfort, and the right end, intense voice discomfort. Based on these instructions, each participant was asked to assess their voice and check the number that represented their level of voice discomfort at the moment.

Then, their voice was recorded before the exercise. These recordings were made individually in a silent room. The emissions were picked up with a professional unidirectional microphone - BLX wireless headset manufactured by Shure ${ }^{\circledR}$ (having a receiver BLX4, bodypack transmitter BLX1, and headset microphone PGA31) - attached to a conventional computer (manufactured by Dell ${ }^{\circledR}$ - Optiplex 3020, Intel Core i3, $4160 \mathrm{U}, 3.60 \mathrm{GHz}, 4 \mathrm{~GB}$, and 64-bit operating system). The participants were asked to stand and emit a prolonged vowel $/ \varepsilon /$ in maximum phonation time (MPT).

The participants then performed the SOVTE technique, blowing into one end of a flexible straw while emitting the vowel / $\mathrm{u} /$ for one minute, with pauses to breathe whenever necessary. One of the researchers timed the exercise and indicated when to stop. The participants filled in the VAS and their voices were recorded after the first (m1), third (m3), fifth (m5), and seventh minutes $(\mathrm{m} 7)$ of exercise. Before recording, they were all instructed on how to correctly perform the vocal technique.

The exercise was made with black drink straws manufactured by Strawplast ${ }^{\circledR}$, measuring $5 \mathrm{~mm}$ wide and $100 \mathrm{~mm}$ long. The straw was positioned at $45^{\circ}$ from the mouth and held by the participant, also sustaining one end of the straw with the lips. The participants remained seated for the technique. The straws were used individually and disposed of after the exercise. Each participant used only one straw throughout the training.

The recordings were submitted to acoustic analysis with the VoxMetria software. The following acoustic parameters were analyzed: mean fundamental frequency (FO) in $\mathrm{Hz}$, noise, GNE, jitter, shimmer, and number of harmonics. The descriptive analysis of the continuous variables (VAS, MPT, noise, F0, GNE, jitter, shimmer, number of harmonics, and age) was made with the measures of central tendency (mean, median) and variability (standard deviation, minimum, and maximum). The Kolmogorov-Smirnov test was applied to assess the distribution of continuous variables. The Friedman test was used to compare each parameter (VAS, MPT, noise, F0, GNE, jitter, shimmer, and the number of harmonics) at different moments both in people with and without voice symptoms. When there were differences between moments, the Wilcoxon test was used to verify at what moment the difference occurred. The Mann-Whitney test was used to compare each parameter (VAS, MPT, noise, F0, GNE, jitter, shimmer, and the number of harmonics) between people with and without symptoms at each moment and in the VoiSS. The analyses were made with the STATA software (Stata Corporation, College Station, Texas), version 12.0, at the $5 \%$ significance level.

\section{RESULTS}

A total of 30 women aged 18 to 39 years (mean of 27.8 years and standard deviation of 5.8 years) participated in the research - 17 with and 13 without voice symptoms.

The comparisons between the moments ( $\mathrm{m} 0$ to $\mathrm{m} 7$ ) in participants with and without symptoms are shown respectively in Tables 1 and 2. None of the variables analyzed revealed significant differences in either group.

There was a significant difference in GNE at the second exercise moment, with a lower value for the group with symptoms. There was also a significant difference between the groups in noise at the second moment, with a higher noise measure for the group with symptoms (Table 3). 
Table 1. Results of the acoustic, maximum phonation time, and visual analog scale analyses of the group of women with voice symptoms $(\mathrm{n}=17)$

\begin{tabular}{|c|c|c|c|c|c|c|}
\hline Parameter & mo & m1 & m3 & m5 & $\mathrm{m7}$ & p-value \\
\hline \multicolumn{7}{|c|}{ FUNDAMENTAL FREQUENCY } \\
\hline Mean & 204.74 & 202.99 & 202.78 & 196.62 & 204.65 & \multirow{3}{*}{0.369} \\
\hline Standard Deviation & 21.15 & 19.92 & 18.02 & 20.03 & 23.68 & \\
\hline Median & 202.59 & 202.83 & 207.84 & 197.72 & 199.34 & \\
\hline \multicolumn{7}{|l|}{ JITTER } \\
\hline Mean & 0.28 & 0.36 & 0.21 & 0.36 & 0.24 & \multirow{3}{*}{0.386} \\
\hline Standard Deviation & 0.32 & 0.54 & 0.24 & 0.44 & 0.23 & \\
\hline Median & 0.14 & 0.13 & 0.11 & 0.14 & 0.16 & \\
\hline \multicolumn{7}{|l|}{ SHIMMER } \\
\hline Mean & 4.95 & 4.17 & 3.54 & 4.56 & 3.12 & \multirow{3}{*}{0.119} \\
\hline Standard Deviation & 4.21 & 2.88 & 3.06 & 4.23 & 3.74 & \\
\hline Median & 4.61 & 3.09 & 2.61 & 2.56 & 2.32 & \\
\hline \multicolumn{7}{|l|}{ GNE } \\
\hline Mean & 0.76 & 0.71 & 0.74 & 0.74 & 0.75 & \multirow{3}{*}{0.459} \\
\hline Standard Deviation & 0.11 & 0.14 & 0.14 & 0.15 & 0.16 & \\
\hline Median & 0.77 & 0.74 & 0.71 & 0.79 & 0.75 & \\
\hline \multicolumn{7}{|c|}{ MAXIMUM PHONATION TIME } \\
\hline Mean & 11.99 & 12.18 & 11.12 & 11.70 & 12.27 & \multirow{3}{*}{0.227} \\
\hline Standard Deviation & 5.26 & 4.33 & 4.28 & 5.23 & 4.95 & \\
\hline Median & 11.17 & 12.42 & 10.43 & 11.60 & 12.33 & \\
\hline \multicolumn{7}{|c|}{ NUMBER OF HARMONICS } \\
\hline Mean & 13.82 & 14.82 & 17.41 & 16.76 & 15.88 & \multirow{3}{*}{0.234} \\
\hline Standard Deviation & 5.31 & 5.40 & 6.09 & 8.00 & 7.30 & \\
\hline Median & 13.0 & 16.0 & 16.0 & 14.0 & 16.0 & \\
\hline \multicolumn{7}{|l|}{ NOISE } \\
\hline Mean & 1.25 & 1.43 & 1.33 & 1.32 & 1.25 & \multirow{3}{*}{0.459} \\
\hline Standard Deviation & 0.45 & 0.57 & 0.60 & 0.61 & 0.65 & \\
\hline Median & 1.18 & 1.33 & 1.42 & 1.12 & 1.27 & \\
\hline \multicolumn{7}{|c|}{ VISUAL ANALOG SCALE } \\
\hline Mean & 2.59 & 2.18 & 1.68 & 2.29 & 2.76 & \multirow{3}{*}{0.762} \\
\hline Standard Deviation & 2.81 & 2.51 & 1.49 & 2.78 & 3.13 & \\
\hline Median & 2.00 & 2.00 & 1.00 & 2.00 & 2.00 & \\
\hline
\end{tabular}

Captions: m = minute; GNE = Glottal-to-noise excitation ratio. 
Table 2. Results of the acoustic, maximum phonation time, and visual analog scale analyses of the group of women without voice symptoms $(n=13)$

\begin{tabular}{|c|c|c|c|c|c|c|}
\hline Parameter & $\mathrm{mo}$ & $\mathrm{m} 1$ & m3 & m5 & m7 & p-value \\
\hline \multicolumn{7}{|c|}{ FUNDAMENTAL FREQUENCY } \\
\hline Mean & 201.92 & 202.93 & 204.80 & 205.29 & 203.38 & \multirow{3}{*}{0.863} \\
\hline Standard Deviation & 20.50 & 15.03 & 17.12 & 15.58 & 16.60 & \\
\hline Median & 198.63 & 205.19 & 203.66 & 209.73 & 204.50 & \\
\hline \multicolumn{7}{|l|}{ JITTER } \\
\hline Mean & 0.31 & 0.14 & 0.12 & 0.14 & 0.19 & \multirow{3}{*}{0.066} \\
\hline Standard Deviation & 0.49 & 0.08 & 0.05 & 0.11 & 0.17 & \\
\hline Median & 0.16 & 0.10 & 0.11 & 0.12 & 0.13 & \\
\hline \multicolumn{7}{|l|}{ SHIMMER } \\
\hline Mean & 3.60 & 2.97 & 2.81 & 2.73 & 2.85 & \multirow{3}{*}{0.110} \\
\hline Standard Deviation & 1.51 & 2.40 & 2.33 & 1.49 & 1.65 & \\
\hline Median & 3.38 & 2.11 & 2.13 & 2.36 & 2.68 & \\
\hline \multicolumn{7}{|l|}{ GNE } \\
\hline Mean & 0.78 & 0.85 & 0.80 & 0.82 & 0.85 & \multirow{3}{*}{0.063} \\
\hline Standard Deviation & 0.20 & 0.08 & 0.15 & 0.11 & 0.13 & \\
\hline Median & 0.90 & 0.85 & 0.81 & 0.83 & 0.90 & \\
\hline \multicolumn{7}{|c|}{ MAXIMUM PHONATION TIME } \\
\hline Mean & 11.45 & 11.01 & 10.79 & 10.75 & 10.58 & \multirow{3}{*}{0.749} \\
\hline Standard Deviation & 4.17 & 3.84 & 4.05 & 3.48 & 4.01 & \\
\hline Median & 11.35 & 9.76 & 10.19 & 10.54 & 10.15 & \\
\hline \multicolumn{7}{|c|}{ NUMBER OF HARMONICS } \\
\hline Mean & 13.92 & 18.46 & 17.54 & 17.46 & 16.23 & \multirow{3}{*}{0.238} \\
\hline Standard Deviation & 6.91 & 5.35 & 5.25 & 6.46 & 5.37 & \\
\hline Median & 11.0 & 17.0 & 18.0 & 18.0 & 16.0 & \\
\hline \multicolumn{7}{|l|}{ NOISE } \\
\hline Mean & 1.17 & 0.86 & 1.06 & 0.97 & 0.87 & \multirow{3}{*}{0.064} \\
\hline Standard Deviation & 0.82 & 0.35 & 0.62 & 0.47 & 0.55 & \\
\hline Median & 0.67 & 0.85 & 1.04 & 0.94 & 0.66 & \\
\hline \multicolumn{7}{|c|}{ VISUAL ANALOG SCALE } \\
\hline Mean & 1.69 & 1.46 & 1.69 & 1.54 & 2.00 & \multirow{3}{*}{0.600} \\
\hline Standard Deviation & 1.84 & 1.90 & 2.29 & 2.26 & 2.71 & \\
\hline Median & 2.00 & 1.00 & 1.00 & 0.00 & 1.00 & \\
\hline
\end{tabular}

Captions: $\mathrm{m}=$ minute; GNE = Glottal-to-noise excitation ratio. 
Table 3. Comparison of the results of the acoustic, maximum phonation time, and visual analog scale analyses between the groups of women with $(n=17)$ and without voice symptoms $(n=13)$

\begin{tabular}{|c|c|c|c|c|c|c|c|c|c|c|}
\hline \multirow{2}{*}{$\begin{array}{l}\text { Parameter } \\
\text { Groups }\end{array}$} & \multicolumn{2}{|c|}{$\mathrm{mo}$} & \multicolumn{2}{|c|}{$\mathrm{m} 1$} & \multicolumn{2}{|c|}{ m3 } & \multicolumn{2}{|c|}{$\mathrm{m} 5$} & \multicolumn{2}{|c|}{$\mathrm{m} 7$} \\
\hline & WS & WOS & WS & WOS & WS & WOS & WS & WOS & WS & WOS \\
\hline \multicolumn{11}{|c|}{ FUNDAMENTAL FREQUENCY } \\
\hline Mean & 204.74 & 201.92 & 202.99 & 202.93 & 202.78 & 204.80 & 196.62 & 205.29 & 204.65 & 203.38 \\
\hline Standard Deviation & 21.15 & 20.50 & 19.92 & 15.03 & 18.02 & 17.12 & 20.03 & 15.58 & 23.68 & 16.60 \\
\hline Median & 202.59 & 198.63 & 202.83 & 205.19 & 207.84 & 203.66 & 197.72 & 209.73 & 199.34 & 204.50 \\
\hline$p$-value & \multicolumn{2}{|c|}{0.754} & \multicolumn{2}{|c|}{0.884} & \multicolumn{2}{|c|}{0.950} & \multicolumn{2}{|c|}{0.174} & \multicolumn{2}{|c|}{0.660} \\
\hline \multicolumn{11}{|l|}{ JITTER } \\
\hline Mean & 0.28 & 0.31 & 0.36 & 0.14 & 0.21 & 0.12 & 0.36 & 0.14 & 0.24 & 0.19 \\
\hline Standard Deviation & 0.32 & 0.49 & 0.54 & 0.08 & 0.24 & 0.05 & 0.44 & 0.11 & 0.23 & 0.17 \\
\hline Median & 0.14 & 0.16 & 0.13 & 0.10 & 0.11 & 0.11 & 0.14 & 0.12 & 0.16 & 0.13 \\
\hline$p$-value & \multicolumn{2}{|c|}{0.769} & \multicolumn{2}{|c|}{0.239} & \multicolumn{2}{|c|}{0.421} & \multicolumn{2}{|c|}{0.093} & \multicolumn{2}{|c|}{0.450} \\
\hline \multicolumn{11}{|l|}{ SHIMMER } \\
\hline Mean & 4.95 & 3.60 & 4.17 & 2.97 & 3.54 & 2.81 & 4.56 & 2.73 & 3.12 & 2.85 \\
\hline Standard Deviation & 4.21 & 1.51 & 2.88 & 2.40 & 3.06 & 2.33 & 4.23 & 1.49 & 3.74 & 1.65 \\
\hline Median & 4.61 & 3.38 & 3.09 & 2.11 & 2.61 & 2.13 & 2.56 & 2.36 & 2.32 & 2.68 \\
\hline$p$-value & \multicolumn{2}{|c|}{0.544} & \multicolumn{2}{|c|}{0.194} & \multicolumn{2}{|c|}{0.368} & \multicolumn{2}{|c|}{0.379} & & 70 \\
\hline GNE & & & & & & & & & & \\
\hline Mean & 0.76 & 0.78 & 0.71 & 0.85 & 0.74 & 0.80 & 0.74 & 0.82 & 0.75 & 0.85 \\
\hline Standard Deviation & 0.11 & 0.20 & 0.14 & 0.08 & 0.14 & 0.15 & 0.15 & 0.11 & 0.16 & 0.13 \\
\hline Median & 0.77 & 0.90 & 0.74 & 0.85 & 0.71 & 0.81 & 0.79 & 0.83 & 0.75 & 0.90 \\
\hline$p$-value & & 48 & & $04^{*}$ & & 60 & 0.1 & 43 & & 57 \\
\hline MAXIMUM PHONA & & & & & & & & & & \\
\hline Mean & 11.99 & 11.45 & 12.18 & 11.01 & 11.12 & 10.79 & 11.70 & 10.75 & 12.27 & 10.58 \\
\hline Standard Deviation & 5.26 & 4.17 & 4.33 & 3.84 & 4.28 & 4.05 & 5.23 & 3.48 & 4.95 & 4.01 \\
\hline Median & 11.17 & 11.35 & 12.42 & 9.76 & 10.43 & 10.19 & 11.60 & 10.54 & 12.33 & 10.15 \\
\hline $\mathrm{p}$-value & & 54 & & 86 & & & 0.7 & 54 & & 79 \\
\hline NUMBER OF HARM & & & & & & & & & & \\
\hline Mean & 13.82 & 13.92 & 14.82 & 18.46 & 17.41 & 17.54 & 16.76 & 17.46 & 15.88 & 16.23 \\
\hline Standard Deviation & 5.31 & 6.91 & 5.40 & 5.35 & 6.09 & 5.25 & 8.00 & 6.46 & 7.30 & 5.37 \\
\hline Median & 13.00 & 11.00 & 16.00 & 17.00 & 16.00 & 18.00 & 14.00 & 18.00 & 16.00 & 16.00 \\
\hline$p$-value & & 16 & & 30 & & & 0.6 & 75 & & 33 \\
\hline NOISE & & & & & & & & & & \\
\hline Mean & 1.25 & 1.17 & 1.43 & 0.86 & 1.33 & 1.06 & 1.32 & 0.97 & 1.25 & 0.87 \\
\hline Standard Deviation & 0.45 & 0.82 & 0.57 & 0.35 & 0.60 & 0.62 & 0.61 & 0.47 & 0.65 & 0.55 \\
\hline Median & 1.18 & 0.67 & 1.33 & 0.85 & 1.42 & 1.04 & 1.12 & 0.94 & 1.27 & 0.66 \\
\hline $\mathrm{p}$-value & & 49 & & $05^{*}$ & & 49 & 0.1 & 49 & & 52 \\
\hline VISUAL ANALOG S & & & & & & & & & & \\
\hline Mean & 2.59 & 1.69 & 2.18 & 1.46 & 1.68 & 1.69 & 2.29 & 1.54 & 2.76 & 2.00 \\
\hline Standard Deviation & 2.81 & 1.84 & 2.51 & 1.90 & 1.49 & 2.29 & 2.78 & 2.26 & 3.13 & 2.71 \\
\hline Median & 2.00 & 2.00 & 2.00 & 1.00 & 1.00 & 1.00 & 2.00 & 0.00 & 2.00 & 1.00 \\
\hline$p$-value & & 47 & & 47 & & 32 & 0.3 & 58 & & 69 \\
\hline
\end{tabular}

Captions: $m=$ minute; $W S=$ with symptoms; WOS $=$ without symptoms. ${ }^{*}$ Mann-Whitney test at the $5 \%$ significance level. 


\section{DISCUSSION}

None of the variables studied had a significant difference between the different moments in the groups of women with and without voice symptoms. This result agrees with research ${ }^{27}$ involving 40 women and eight men with and without laryngeal lesions. They used hard plastic straws $(8.7 \mathrm{~cm} \times 1.5 \mathrm{~mm}$.), and the technique was performed for 1 minute. The authors reported that F0, jitter, and shimmer had rather discrete and nonsignificant variations.

A study ${ }^{28}$ with 55 dysphonic and non-dysphonic women, using hard plastic straws measuring $8.7 \mathrm{~cm}$ by $1.5 \mathrm{~mm}$, also pointed out that some parameters, such as F0, jitter, shimmer, GNE, and noise did not change in normophonic women over 7 minutes performing the exercise. In the dysphonic women, there were positive responses up to the fifth minute, peaking at the third minute, and less effort to speak. Another study ${ }^{7}$ carried out with 23 women without voice symptoms, using hard plastic straws $(8.7 \mathrm{~cm} \times 1.5 \mathrm{~mm})$, pointed out that the F0 decreased after the exercise. The other acoustic parameters of F0 variability in speech, voice irregularity, and GNE were similar before and after the exercise, which lasted 1 minute.

The literature indicates that the SOVTE has many benefits for voice quality and projection. Studies comparing the recordings made before and after the technique report improved auditory-perceptual aspects (such as resonance and voice projection), improved F0 values, decreased noise, improved spectrographic tracing, and a greater number of harmonics ${ }^{7,29}$. In the present study, no significant variability was identified in any of the acoustic parameters researched or in the self-assessed voice discomfort.

A study ${ }^{28}$ used the VAS to quantify the participants' perception of their effort to speak before and after 1, 3, 5 , and 7 minutes of the high-resistance straw phonation exercise and verified that the perception of effort to speak diminished after 1 and 3 minutes and increased back after 5 and 7 minutes of exercise. Other pieces of research ${ }^{7,27}$, though, using other types of voice self-assessment with multiple-choice questionnaires on perceived voice and sensation changes after the exercise, obtained positive straw phonation results. These studies ${ }^{7,28}$ had different results from the present one, raising suspicion that the dimensions and material of the straw might interfere with the results.

A study that assessed the effects of straw phonation after $1,3,5$, and 7 minutes performing the technique ${ }^{28}$ revealed an increase in post-exercise MPT. The results differ from the findings in the present research, which did not reveal a significant improvement in this variable. A possible explanation for this divergence may be the difference in material and diameter of the straws used in the studies. The study by Paes ${ }^{28}$ used a more resistant straw, as it was only $1.5 \mathrm{~mm}$ wide, which may have favored glottal closure, consequently influencing the MPT.

In the present study, the comparison between groups at the second moment revealed a significant difference in GNE and noise. The group with voice symptoms had a lower GNE value at all moments, which was not expected. Also, the value decreased after 1 minute, while the GNE increased in the group without symptoms in $\mathrm{m} 1$, which explains the statistical difference in this variable. The GNE is a noise-related acoustic measure produced by vocal fold oscillation; the noise, in its turn, is related to the aperiodic components of the sound signal ${ }^{30}$. Higher noise values were expected from people with symptoms, as the noise is related to what our ears perceive as roughness. However, there was a difference only at the second assessment moment (after 1 minute), which was when people without voice symptoms had the greatest decrease in value in this variable. The decrease in noise at the first minute of performing the exercise was accompanied by an increase in the number of harmonics.

Regarding the SOVTE, it must be said that the nonlinear voice theory suggests that the vocal tract modifies the vibration patterns of the vocal folds by changing the acoustic impedance of the voice filter, also filtering the sound produced in the glottal source ${ }^{29}$. Hence, researching the applicability of the SOVTE as a therapeutic resource is both relevant and important.

The limitations of this research included the small sample size, the absence of male participants, not separating occupational voice users, and not performing a laryngeal examination of the participants. Further research is warranted, with more participants, including males and a broader age range, to compare people's results by age groups, separating the groups based on their laryngeal diagnosis.

\section{CONCLUSION}

There was no significant difference in the acoustic parameters analyzed or in the self-perception of voice discomfort in women with and without voice symptoms before performing the straw phonation technique 
and after the first, third, fifth, and seventh minutes of exercise.

The GNE and noise had statistically significant differences between the groups at the second moment performing the technique, with lower GNE and higher noise values in the group with voice symptoms.

\section{REFERENCES}

1. Fantini M, Succo G, Crosetti E, Torre AB, Demo $R$, Fussi $F$. Voice quality after a semi-occluded vocal tract exercise with a ventilation mask in contemporary commercial singers: acoustic analysis and self-assessments. J Voice. 2017;31(3):336-41.

2. Christmann M, Cielo C. Acoustic and auditory perception effects of the voice therapy technique finger kazoo in adult women. $\mathrm{J}$ Voice. 2017;31(3):390.e9-15.

3. Guzman M, Laukkanen AM, Krupa P, Horáček J, Švec JG, Geneid A. Vocal tract and glottal function during and after vocal exercising with resonance tube and straw. J Voice. 2013;27(4):523.e19-33.

4. Dargin T, Searl J. Semi-occluded vocal tract exercises: aerodynamic and electroglottographic measurements in singers. $\mathrm{J}$ Voice. 2015;29(2):155-64.

5. Andrade PA, Wood G, Ratcliffe P, Epstein R, Pjiper A, Svec JG. Electroglottographic study of seven semi-occluded exercises: LaxVox, straw, lip-trill, tongue-trill, humming, hand-over-mouth, and tongue-trill combined with hand-over-mouth. J Voice. 2014;28(5):589-95.

6. Siqueira ACO, Santos NEP, Souza BO, Nogueira LLCR, Furlan RMMM. Immediate vocal effects produced by the Shaker device in women with and without vocal complaints. CoDAS. 2021;33(3):e20200155.

7. Sampaio M, Oliveira G, Behlau M. Investigation of the immediate effects of two semi-ocluded vocal tract exercises. Pró-fono R. Atual. Cientif. 2008;20(5):261-6.

8. Duke E, Plexico LW, Sandage MJ, Hoch M. The effect of traditional singing warm-up versus semioccluded vocal tract exercises on the acoustic parameters of singing voice. $\mathrm{J}$ Voice. 2015;29(6):727-32.

9. Souza RC, Masson MLV, Araújo TM. Effects of the exercise of the semi-occluded vocal tract with a commercial straw in the teachers' voice. Rev. CEFAC. 2017;19(3):360-70.
10. Siracusa MGP, Oliveira G, Madazio G, Behlau M. Immediate effect of sounded blowing exercise in the elderly voice. J Soc Bras Fonoaudiol. 2011;23(1):27-31.

11. Guzmán M, Higueras D, Fincheira $C$, Muñuoz D, Guajardo C. Efectos acústicos inmediatos de una secuencia de ejercicios vocales con tubos de resonancia. Rev. CEFAC. 2012;14(3):471-80.

12. Titze I. Voice training and therapy with a semi-occluded vocal tract: rational and scientific underpinnings. J Speech Lang Rear Res. 2006;49(2):448-59.

13. Paes S, Zambon F, Yamasaki R, Simberg S, Behlau $M$. Immediate effects of the Finnish resonance tube method on behavioral dysphonia. $\mathrm{J}$ Voice. 2013;27(6):717-22.

14. Silva AR, Ghirardi AC, Reisner MR, Paul S. An exact analytical model for the relationship between flow resistance and geometric properties of tubes used in semi-occluded vocal tract exercises. $\mathrm{J}$ Voice. 2019;33(5):585-90.

15. Wistbacka G, Andrade PA, Simberg S, Hammarberg B, Södersten M, Švec JG. Resonance tube phonation in water: the effect of tube diameter and water depth on back pressure and bubble characteristics at different airflows. $\mathrm{J}$ Voice. 2018;32(1):126.e11-22.

16. Andrade PA, Wistbacka G, Larsson $H$, Sodersten $M$, Hammarberg $B$, Simberg $S$. The flow and pressure relationships in different tubes commonly used for semi-occluded vocal tract exercises. J Voice. 2016;30(1):36-41.

17. Andrade BMR, Valença EHO, Salvatori R, Souza AHO, Oliveira-Neto LA, Oliveira AHA. Effects of therapy with semi-occluded vocal tract and choir training on voice in adult individuals with congenital, isolated, untreated growth hormone deficiency. J Voice. 2019;33(5):808.e1-808.e5.

18. Laukkanen AM, Titze IR, Hoffman H, Finnegan E. Effects of a semioccluded vocal tract on laryngeal muscle activity and glottal adduction in a single female subject. Folia Phoniatr Logop. 2008;60(6):298-311 .

19. Granqvist S, Hertegard S, Holmqvist S, Larsson $\mathrm{H}$, Lindestad PA. Resonance tube phonation in water: High-speed imaging, electroglottographic and oral pressure observations of vocal fold vibrations - a pilot study. Logoped Phoniatr Vocol. 2015;40(3):113-21. 
20. Robieux C, Galant C, Lagier A, Legou T, Giovanni A. Direct measurement of pressures involved in vocal exercises using semi-occluded vocal tracts. Logoped Phoniatr Vocol. 2015;40(3):106-24.

21. Sovijärvi A. Nya metoder vid behandling av röstrubbningar. Nordisk Tidskrift for Tale og Stemme. 1969;3:121-31.

22. Figueiredo DC, Souza PRF, Gonçalves MIR, Biase NG. Auditory perceptual, acoustic, computerized and laryngological analysis of young smokers' and nonsmokers' voice. Rev. Bras Otorrinolaringol. 2003;69(6):791-9.

23. Oliveira IB, Fernandez ES, Gargantini EP. Phonatory deviation diagram in organic dysphonia by neoplasia. Rev. CEFAC. 2015;17(2):364-73.

24. Hillenbrand J. A methodological study of perturbation and additive noise in synthetically generated voice signals. J Speech Hear Res. 1987;30(4):448-61.

25. Moreti F, Zambon F, Oliveira G, Behlau M. Equivalência cultural da versão brasileira da Voice Symptom Scale - VoiSS. J Soc Bras Fonoaudiol. 2011;23(4):398-400.

26. Borg G. Escalas de Borg para a dor e o esforço percebido. São Paulo: Manole; 2000.

27. Costa CB, Costa LHC, Oliveira G, Behlau M. Immediate effects of the phonation into a straw exercise. Braz Otorhinolaryngol. 2011;77(4):461-5.

28. Paes SM, Behlau M. Dosage dependent effect of highresistance straw exercise in dysphonic and nondysphonic women. CoDAS. 2017;29(1):e20160048.

29. Cielo CA, Lima JPM, Christmann MK, Brum R. Semioccluded vocal tract exercises: literature review. Rev. CEFAC. 2013;15(6):1679-89.

30. Carrasco E, Oliveira G, Behlau M. Análise perceptivo-auditiva e acústica da voz de indivíduos gagos. Rev. CEFAC. 2010;12(6):925-35. 